\title{
Kinetics of Permanganate Consumption by Natural Oxidant Demand in Aquifer Solids
}

\author{
Ki Young Cha, ${ }^{1, *}$ Michelle Crimi, ${ }^{2}$ Michael A. Urynowicz, ${ }^{3}$ and Robert C. Borden ${ }^{1}$ \\ ${ }^{1}$ Department of Civil, Construction, and Environmental Engineering, North Carolina State University, Raleigh, North Carolina. \\ 2Institute for a Sustainable Environment, Clarkson University, Potsdam, New York. \\ ${ }^{3}$ Department of Civil and Architectural Engineering, University of Wyoming, Laramie, Wyoming.
}

Received: April 26, $2011 \quad$ Accepted in revised form: August 15, 2011

\begin{abstract}
Effectiveness of permanganate $\left(\mathrm{MnO}_{4}^{-}\right)$injection for in situ chemical oxidation is often controlled by the natural oxidant demand (NOD) of the aquifer solids. In this work, a simple procedure was developed and applied to generate a database of NOD kinetic parameters for six different models for 50 different aquifer materials. Representing oxidant consumption as an initial instantaneous reaction with a portion of the total NOD and as a second order reaction between $\mathrm{MnO}_{4}^{-}$and the remainder of the NOD provided a good match with experimental results from batch studies, without imposing an unnecessary computational burden. Wide variations in NOD parameters were observed including total NOD, fraction fast/instantaneous, and second order rate coefficients. Approximately $80 \%$ of the samples had a total NOD between 0.002 and $0.158 \mathrm{mmol} / \mathrm{g}$ with a median value of $0.028 \mathrm{mmol} / \mathrm{g}$. Most of the NOD present was slow reacting, so $\mathrm{MnO}_{4}^{-}$could persist for weeks to months once the fast reacting fraction is depleted. Total NOD was not correlated with fraction fast/instantaneous or the reaction rate coefficients, thus indicating that NOD reactivity is independent of the total amount of NOD. Results from 48-h NOD measurements were also shown to be poor predictors of total NOD and should not be used to estimate long-term $\mathrm{MnO}_{4}^{-}$consumption.
\end{abstract}

Key words: in situ chemical oxidation; ISCO; kinetics; models; natural oxidant demand; NOD; permanganate

\section{Introduction}

$I^{N}$ $N$ SITU CHEMICAL OXIDATION (ISCO) using permanganate $\left(\mathrm{MnO}_{4}^{-}\right)$can be very effective for treatment of chlorinated ethenes including perchloroethene, trichloroethene, and some aromatic hydrocarbons (naphthalene, phenanthrene, pyrene, and phenols) (Yan and Schwartz, 1999; Siegrist et al., 2001). When $\mathrm{MnO}_{4}^{-}$is injected into the subsurface, $\mathrm{MnO}_{4}^{-}$accepts three electrons and is subsequently reduced to $\mathrm{MnO}_{2}$ solids (Siegrist et al., 2001). A portion of the electrons consumed are from oxidation of the target contaminant, and a portion are from the aquifer material including natural organic matter (NOM), reduced iron, manganese, and sulfur minerals (Yan and Schwartz, 1999; Siegrist et al., 2001; Mumford et al., 2005; Hønning et al., 2007; Urynowicz, 2008; Urynowicz et al., 2008). The amount of $\mathrm{MnO}_{4}^{-}$that reacts with nontarget chemicals is often referred to as natural oxidant demand (NOD) and can vary from $<1 \%$ to over $99 \%$ of the total $\mathrm{MnO}_{4}^{-}$demand, depending on the contaminant concentration and aquifer char-

${ }^{*}$ Corresponding author: Department of Civil, Construction, and Environmental Engineering, North Carolina State University, Campus Box 7908, Raleigh, NC 27695. Phone: 919-515-7207; Fax: 919-5157908; E-mail: kycha@ncsu.edu acteristics. When NOD is high, then contaminant treatment efficiency may be less than desired due to nonproductive consumption of $\mathrm{MnO}_{4}^{-}$(Siegrist et al., 2001; Urynowicz, 2008).

The reaction between $\mathrm{MnO}_{4}^{-}$and NOD will depend on $\mathrm{MnO}_{4}^{-}$concentration and reaction time, as some fraction of the NOD may react slowly. Mumford et al. (2005) found that NOD exerted during short-term column experiments was much lower than that in long-term batch incubations. Even after 21 weeks incubation, the NOD in the soil was not completely oxidized and $\mathrm{MnO}_{4}^{-}$continued to be depleted. Several investigators (Yan and Schwartz, 1999; Siegrist et al., 2001; Mumford et al., 2005; Urynowicz et al., 2008) have reported that the measured NOD varies with the $\mathrm{MnO}_{4}^{-}$concentration and reaction time. Higher concentrations of $\mathrm{MnO}_{4}^{-}$commonly result in higher measured values of NOD (Siegrist, 2001; Hønning et al., 2007; Urynowicz et al., 2008). To reflect these observations, $\mathrm{MnO}_{4}^{-}$consumption is commonly modeled as a second order reaction between $\mathrm{MnO}_{4}^{-}$and NOD (Zhang and Schwartz, 2000; Urynowicz et al., 2008; Xu and Thomson, 2009).

More recent work has shown that NOD is composed of several components or fractions with varying reactivity (Mumford et al., 2005; Hønning et al., 2007; Urynowicz et al., 2008; Xu and Thomson, 2009). Ideally, NOD would be 
represented with a continuum of reaction rates where the less reactive fraction becomes progressively more important as the more reactive NOD fraction is depleted. However, studies by Urynowicz et al. (2008) and $\mathrm{Xu}$ and Thomson (2009) suggest that $\mathrm{MnO}_{4}^{-}$consumption by NOD can be reasonably well described by assuming that NOD is composed of disparate fast and slow fractions. In batch experiments conducted by Urynowicz et al. (2008), the fast NOD appeared to be consumed within about $48 \mathrm{~h}$, followed by a slower depletion of $\mathrm{MnO}_{4}^{-}$at rates of 0.024 to 0.13 day $^{-1}$, depending on $\mathrm{MnO}_{4}^{-}$ dose. $\mathrm{Xu}$ and Thomson (2009) found that a fraction of NOD was depleted in a few hours followed by much slower deg- radation, where the slow NOD reaction rate varied from 0.014 to $0.72 \mathrm{~L} / \mathrm{mmol}$-day with a median value of $0.077 \mathrm{~L} / \mathrm{mmol}-$ day, in batch experiments.

\section{Objective and Approach}

The performance of ISCO systems can potentially be improved by using numerical models to simulate ISCO with $\mathrm{MnO}_{4}^{-}$under realistic conditions using spatially heterogeneous, three-dimensional flow, transport, and chemical reaction models. However, simulation of ISCO with $\mathrm{MnO}_{4}^{-}$ requires constitutive relationships that accurately represent

Table 1. Natural Oxidant Demand and $\mathrm{MnO}_{4}{ }^{-}$Kinetic Relationships for All Six Models

\begin{tabular}{|c|c|c|}
\hline Model & Equation & Description \\
\hline 1 & $\frac{d\left(\mathrm{MnO}_{4}^{-}\right)}{d t}=-k_{0}$ & Zero-order loss of $\mathrm{MnO}_{4}^{-}$ \\
\hline 2 & $\frac{d\left(\mathrm{MnO}_{4}^{-}\right)}{d t}=-k_{1 M}\left(\mathrm{MnO}_{4}^{-}\right)$ & First-order loss of $\mathrm{MnO}_{4}^{-}$ \\
\hline 3 & $\begin{array}{c}\frac{d(N O D)}{d t}=-k_{1 N}(N O D) \\
\frac{d\left(M_{n} O_{4}^{-}\right)}{d t}=-\rho_{B} k_{1 N}(N O D) / n\end{array}$ & First-order loss of NOD \\
\hline 4 & $\begin{aligned} \frac{d\left(\mathrm{MnO}_{4}^{-}\right)}{d t} & =-\rho_{B} k_{2}(\mathrm{NOD})\left(\mathrm{MnO}_{4}^{-}\right) / n \\
\frac{d(\mathrm{NOD})}{d t} & =-k_{2}(\mathrm{NOD})\left(\mathrm{MnO}_{4}^{-}\right)\end{aligned}$ & $\begin{array}{l}\text { Second-order loss of } \mathrm{MnO}_{4}^{-} \\
\text {and NOD }\end{array}$ \\
\hline 5 & $\begin{aligned} \frac{d\left(\mathrm{MnO}_{4}^{-}\right)}{d t}= & -\rho_{B} k_{2 F}\left(\mathrm{NOD}_{F}\right)\left(\mathrm{MnO}_{4}^{-}\right) / n \\
& -\rho_{B} k_{2 S}\left(\mathrm{NOD}_{S}\right)\left(\mathrm{MnO}_{4}^{-}\right) / n\end{aligned}$ & $\begin{array}{l}\text { Second-order loss of } \mathrm{MnO}_{4}^{-} \text {with fast } \\
\text { and slow NOD }\end{array}$ \\
\hline & $\begin{array}{l}\frac{d\left(N O D_{F}\right)}{d t}=-k_{2 F}\left(N_{F} D_{F}\right)\left(M n O_{4}^{-}\right) \\
\frac{d\left(N O D_{S}\right)}{d t}=-k_{2 S}\left(N O D_{S}\right)\left(M_{n} O_{4}^{-}\right)\end{array}$ & \\
\hline \multirow[t]{3}{*}{6} & $\begin{array}{l}\text { When concentration of } \mathrm{MnO}_{4}^{-}>\left(N O D_{I}\right) \rho_{B} / n \\
\mathrm{MnO}_{4}^{-}=M n \mathrm{O}_{4}^{-}-\rho_{B}\left(\mathrm{NOD}_{I}\right) / n \text { and } \mathrm{NOD}_{I}=0 \\
\text { otherwise }\end{array}$ & $\begin{array}{l}\text { Second-order loss of } \mathrm{MnO}_{4}^{-} \text {with } \\
\text { instantaneous and slow NOD }\end{array}$ \\
\hline & $\mathrm{MnO}_{4}^{-}=0$ and $N O D_{I}=N O D_{I}-\left(\mathrm{MnO}_{4}^{-}\right) n / \rho_{B}$ & \\
\hline & $\begin{array}{l}\text { Then } \\
\frac{d\left(\mathrm{MnO}_{4}^{-}\right)}{d t}=-\rho_{B} k_{2 S}\left(\mathrm{NOD}_{S}\right)\left(\mathrm{MnO}_{4}^{-}\right) / n \\
\frac{d\left(\mathrm{NOD}_{S}\right)}{d t}=-k_{2 S}\left(\mathrm{NOD}_{S}\right)\left(\mathrm{MnO}_{4}^{-}\right)\end{array}$ & \\
\hline
\end{tabular}

\footnotetext{
$t$, Time (day).
}

$N$, Porosity (liter of water per liter of reactor).

$\rho_{B}$, Aquifer solids bulk density (kg dry soil per liter of reactor).

$\mathrm{MnO}_{4}^{-}, \mathrm{MnO}_{4}^{-}$concentration $(\mathrm{mmol} / \mathrm{L})$.

$\mathrm{NOD}$, Total NOD concentration $(\mathrm{mmol} / \mathrm{kg})$.

$N O D_{F}$, Fast NOD concentration $(\mathrm{mmol} / \mathrm{kg})$.

$N O D_{S}$, Slow NOD concentration $(\mathrm{mmol} / \mathrm{kg})$.

$N O D_{I}$ Instantaneous NOD concentration $(\mathrm{mmol} / \mathrm{kg})$.

$k_{0}$, Zero-order $\mathrm{MnO}_{4}^{-}$consumption rate (mmol/L-day).

$k_{1 M}$, First-order $\mathrm{MnO}_{4}^{-}$consumption rate $\left(\right.$day $\left.^{-1}\right)$.

$k_{1 N}$, First-order NOD consumption rate $\left(\right.$ day $\left.^{-1}\right)$.

$k_{2}$, Second-order NOD consumption rate ( $\mathrm{L} / \mathrm{mmol}$-day).

$k_{2 F}$, Second-order Fast NOD consumption rate (L/mmol-day).

$k_{2 S}$, Second-order Slow NOD consumption rate (L/mmol-day).

NOD, natural oxidant demand. 
the kinetics of $\mathrm{MnO}_{4}^{-}$consumption by NOD for a range of conditions. Ideally, these kinetic models could be applied without imposing an excessive computational burden, using parameters estimated from standard NOD test protocols.

In the work presented here, six different kinetic models were fit to data from batch NOD tests on 50 different aquifer samples with varying $\mathrm{MnO}_{4}^{-}$concentrations and/or aquifer solid to water ratios following ASTM D 7262-07 (2007). The six models evaluated are summarized in Table 1. Subroutines were developed within MS Excel for each model and applied to automatically estimate model parameters for each aquifer sample. Results of this work were used to identify the models that best fit the experimental results and to generate a database of parameters which can be used in future modeling studies.

The models examined in this work included simple zeroand first-order single parameter models (1, 2, and 3) and second-order models incorporating the effects of oxidant concentration and NOD concentration (4, 5, and 6). For Models 5 and 6, NOD was assumed to be composed of slowly reacting and fast/instantaneously reacting components. This work aimed at developing relatively simple models that could accurately represent reaction kinetics without imposing an excessive computational burden and, therefore, only terms that could be estimated from the standard ASTM test protocol were used in the simulations.

\section{NOD measurement and parameter estimation protocol}

A total of 50 samples of aquifer solids were analyzed from twelve different facilities located throughout the United States (Supplementary Table S1), where ISCO with $\mathrm{MnO}_{4}^{-}$was being considered a possible remedial alternative. NOD was measured following ASTM D 7262-07 (2007) by reacting airdried aquifer solids in glass reactor bottles with analytical grade $\mathrm{KMnO}_{4}$ (Carus Corporation, Peru, IL) and deionized water. However, the reaction period was extended to better characterize the longer-term consumption of $\mathrm{MnO}_{4}^{-}$by slowly reacting NOD. Samples were stored at room temperature and mixed once per day by inverting the bottles. $\mathrm{MnO}_{4}^{-}$ concentrations were monitored for up to 41 days by measuring absorbance at $525 \mathrm{~nm}$ (Crimi and Siegrist, 2005). Typically, NOD tests were run with low $(200-600 \mathrm{mg} / \mathrm{L})$, medium (1000-3000 mg/L), and high (4500-10,000 mg/L) $\mathrm{KMnO}_{4}$ concentrations. The aquifer solid to water ratio was varied, thus resulting in $\mathrm{KMnO}_{4}$ doses ranging from 5.8 to 61 $\mathrm{mmol} / \mathrm{kg}$. The experimental conditions for each sample are listed in Supplementary Table S2. Shorter test periods and/or higher doses were used when $\mathrm{MnO}_{4}^{-}$was rapidly consumed.

For each of the six kinetic models, an MS Excel Visual Basic for Application subroutine was developed by using a fourthorder Runge-Kutta solution of the ordinary differential equations. The computation time step was set to $5 \%$ of the experimental time step to minimize computational errors. For each aquifer solid, a single value for each NOD parameter was assumed, and the model was used to estimate the change in $\mathrm{MnO}_{4}^{-}$concentration with time for every experimental treatment. The model error was defined as the difference between simulated and measured $\mathrm{MnO}_{4}^{-}$concentration. The global root-mean-square error (RMSE) was calculated by using the error at every time point for every experimental treatment (varying aquifer solid:water ratios and varying aqueous $\mathrm{MnO}_{4}^{-}$concentrations) and replicates for each aquifer solid. The Solver function in MS Excel was used to search for the parameter set that minimized the RMSE using a quasi-Newton search method. From this procedure, a single set of NOD parameters were generated for each aquifer solid that minimized the RMSE in predicted $\mathrm{MnO}_{4}^{-}$concentration for all experimental conditions. Additional details on the
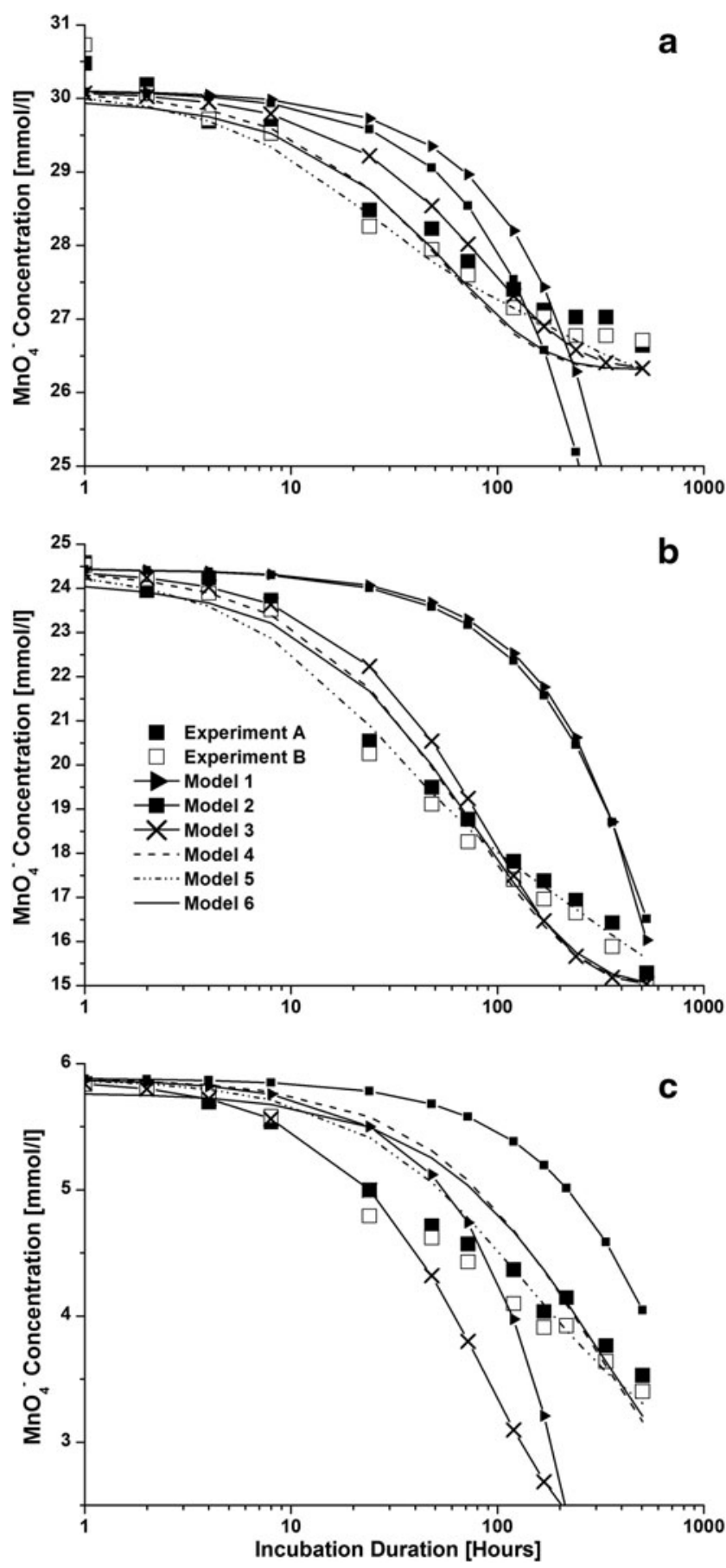

FIG. 1. Comparison of simulated and observed $\mathrm{MnO}_{4}^{-}$ concentrations for aquifer sample YT-YS2 with (a) 30.1 mmol/L initial $\mathrm{MnO}_{4}^{-}$concentration and $0.38 \mathrm{~g}$ solids per $\mathrm{mL}$ water; (b) $24.5 \mathrm{mmol} / \mathrm{L} \mathrm{MnO}_{4}^{-}$and $0.38 \mathrm{~g}$ solids $/ \mathrm{mL}$; and (c) $5.9 \mathrm{mmol} / \mathrm{L} \mathrm{MnO}_{4}^{-}$and $0.95 \mathrm{~g}$ solids $/ \mathrm{mL} \mathrm{MnO}_{4}^{-}$, permanganate. 

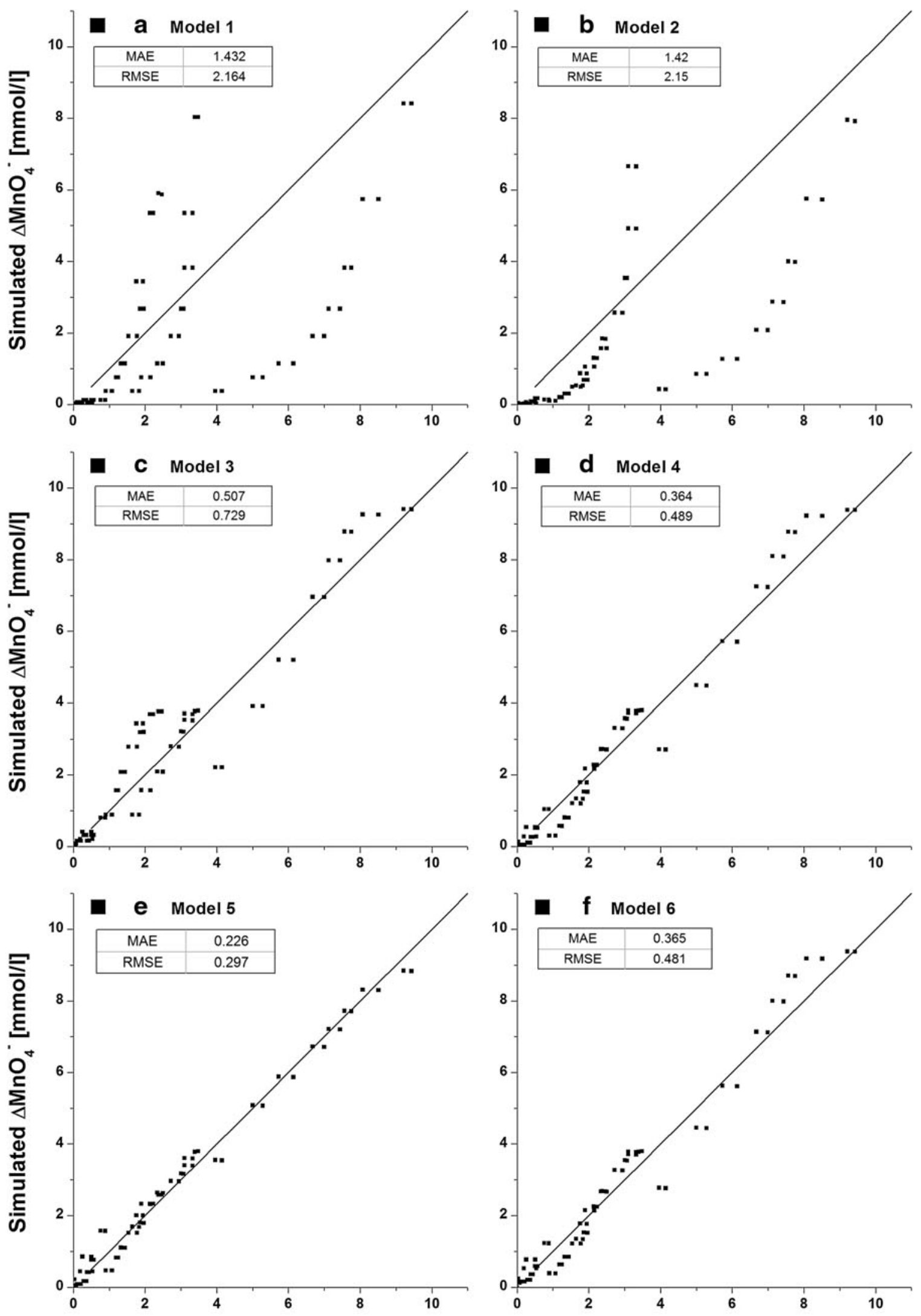

\section{Experimental $\triangle \mathrm{MnO}_{4}^{-}[\mathrm{mmol} / \mathrm{l}]$}

FIG. 2. Simulated versus observed $\Delta \mathrm{MnO}_{4}^{-}$for all treatments of YT-YS2: (a) Model 1, (b) Model 2, (c) Model 3, (d) Model 4, (e) Model 5, and (f) Model 6. Solid line represents a perfect match between simulated and observed $\Delta \mathrm{MnO}_{4}^{-}$. 
numerical solution techniques are provided in Borden et al. (2010).

\section{Model evaluation}

Each of the six models were fit to the NOD experimental results for each of the 50 aquifer solids. Figure 1 shows typical results for a single aquifer solid (YT-YS2). Aquifer sample YTYS2 was tested in duplicate (Experiment A and Experiment B) with three experimental treatments $\left(\mathrm{MnO}_{4}^{-}=30.1,24.5\right.$, or 5.9 $\mathrm{mM}$; solid:water ratio $=0.38$ or $0.95 \mathrm{~g}$ aquifer solids per $\mathrm{mL}$ water) over 22 days, thereby resulting in a total of 78 concentration measurements. Over the 22-day experimental period, $\mathrm{MnO}_{4}^{-}$concentration declined by up to $9 \mathrm{mM}$ as the oxidant was consumed by NOD. The difference in $\mathrm{MnO}_{4}^{-}$ consumption between the three different treatments is presumably due to differences in initial $\mathrm{MnO}_{4}^{-}$concentration and aquifer solids to water ratio.

The lines shown in Fig. 1 are simulation results generated by using the single set of coefficients for each model. The model coefficients were determined by (a) calculating the error between simulated and observed concentration; (b) calculating the RMSE for the entire YT-YS2 data set; and (c) searching for the model coefficients that minimized the RMSE. Models 1 and 2 do not follow the overall trends in the data and provide a poor match to the experimental results for all three treatments. Model 3 provides a reasonably good fit to the two higher concentration experiments (Fig. 1a, b), but significantly underestimates the $\mathrm{MnO}_{4}^{-}$concentrations during much of the low concentration experiment (Fig. 1c). In contrast, Models 4, 5, and 6 provide a reasonably good match with the general trends in $\mathrm{MnO}_{4}^{-}$concentration versus time for all three treatments.

Data from Fig. 1 are replotted in Fig. 2 to better illustrate the performance of the different models. For every experimental measurement, the change in $\mathrm{MnO}_{4}^{-}$concentration $\left(\Delta \mathrm{MnO}_{4}^{-}\right)$was computed as the difference between the initial concentration and the measured concentration and compared with the simulated $\Delta \mathrm{MnO}_{4}^{-}$for each model. Figure 2 shows a comparison of simulated and experimental $\Delta \mathrm{MnO}_{4}^{-}$for all 78 measurements made with the YT-YS2 aquifer solids. Ideally, all the data would plot along the solid 45-degree line, thus indicating a perfect match between simulated and observed values. For Models 1 and 2 (Fig. 2a, b), the data points show clear trends above and below the 1:1 line, thus indicating a very poor match with the experimental results. For Model 3 (Fig. 2c), the data generally plot along the 1:1 line, thus indicating a relatively good match to the data. However, there are areas where groups of points are clustered above or below the 1:1 line, thus indicating some underlying trend that is not captured by the model. In contrast, the data points for Models 4, 5, and 6 plot along the 45-degree line with no obvious trends in $\Delta \mathrm{MnO}_{4}^{-}$. Model 5 with four calibration parameters provides the lowest mean absolute error (MAE) and RMSE, indicating that it provided the best fit to the YT-YS2 experimental results. However, Model 6, with three calibration parameters, provided a relatively good fit to the experimental data with both MAE and RMSE $<5 \%$ of the maximum $\Delta \mathrm{MnO}_{4}^{-}$.

Figure 3 shows cumulative frequency distributions for the MAE and RMSE for each model for all 50 aquifer solid samples. Model 5 (4 parameters), Model 6 (3 parameters), and
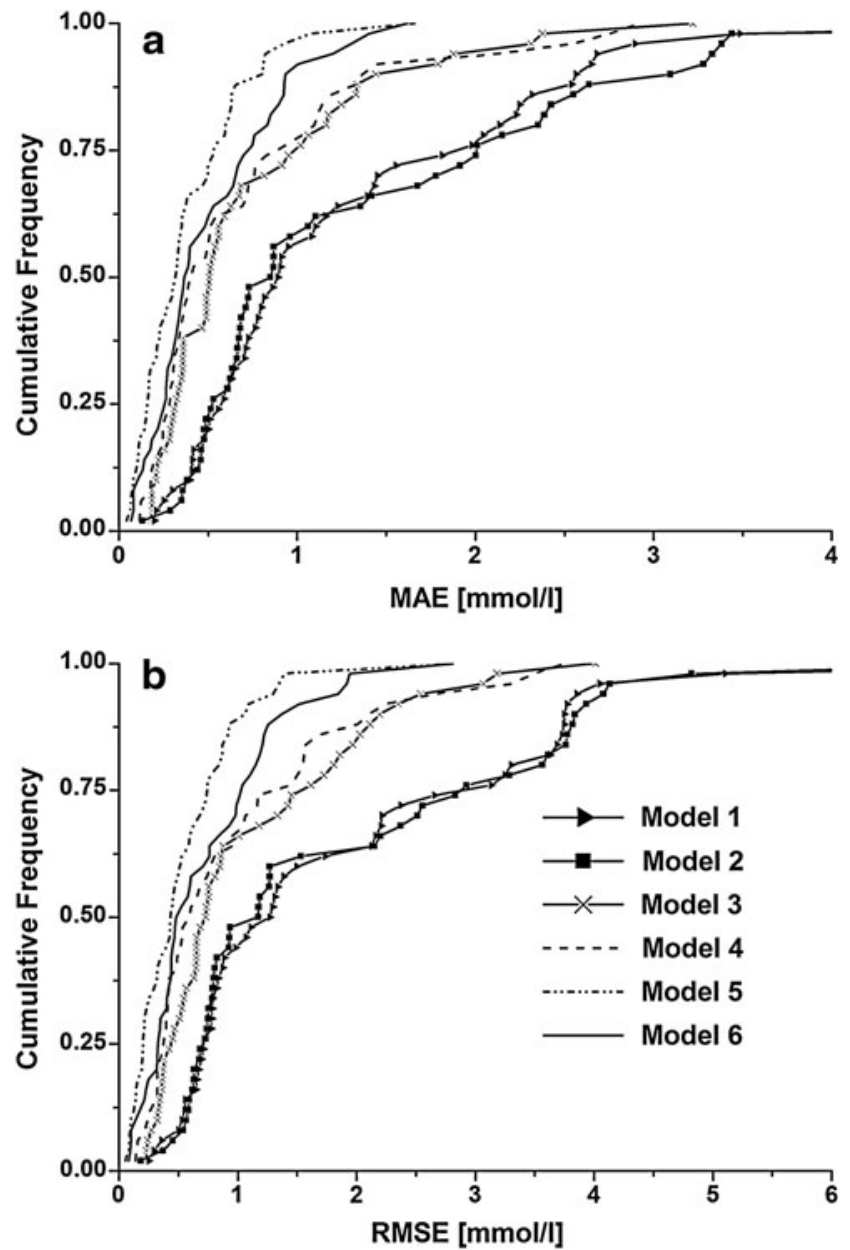

FIG. 3. Cumulative frequency distributions of (a) mean absolute error (MAE) and (b) root-mean-square error (RMSE) for Models 1-6 using NOD data from 50 aquifer solids. NOD, natural oxidant demand.

Model 4 (2 parameters) provide relatively good fits (low MAE and RMSE) to the experimental data for more than $50 \%$ of the aquifer samples. However, for the worst $10 \%-20 \%$ of the samples (highest MAE and RMSE), the performance of Models 5 and 6 is substantially better than that of Model 4 .

To provide an overall estimate of model performance, the data on model fit to all 50 aquifer solids were pooled together (2894 $\mathrm{MnO}_{4}^{-}$measurements) and used to compute the global

Table 2. Mean Absolute Error ANd Root-Mean-Souare ERror for Models 1-6 Using Pooled Data From 50 Aquifer Solids

\begin{tabular}{lccc}
\hline Model & $\begin{array}{c}\text { \# of } \\
\text { parameters }\end{array}$ & $\begin{array}{c}\text { MAE } \\
(\mathrm{mmol} / \mathrm{L})\end{array}$ & $\begin{array}{c}\text { RMSE } \\
(\mathrm{mmol} / \mathrm{L})\end{array}$ \\
\hline 1 & 1 & 1.31 & 2.40 \\
2 & 1 & 1.36 & 2.38 \\
3 & 2 & 0.81 & 1.46 \\
4 & 2 & 0.70 & 1.22 \\
5 & 4 & 0.46 & 0.80 \\
6 & 3 & 0.58 & 0.98 \\
\hline
\end{tabular}

MAE, mean absolute error; RMSE, root-mean-square error. 

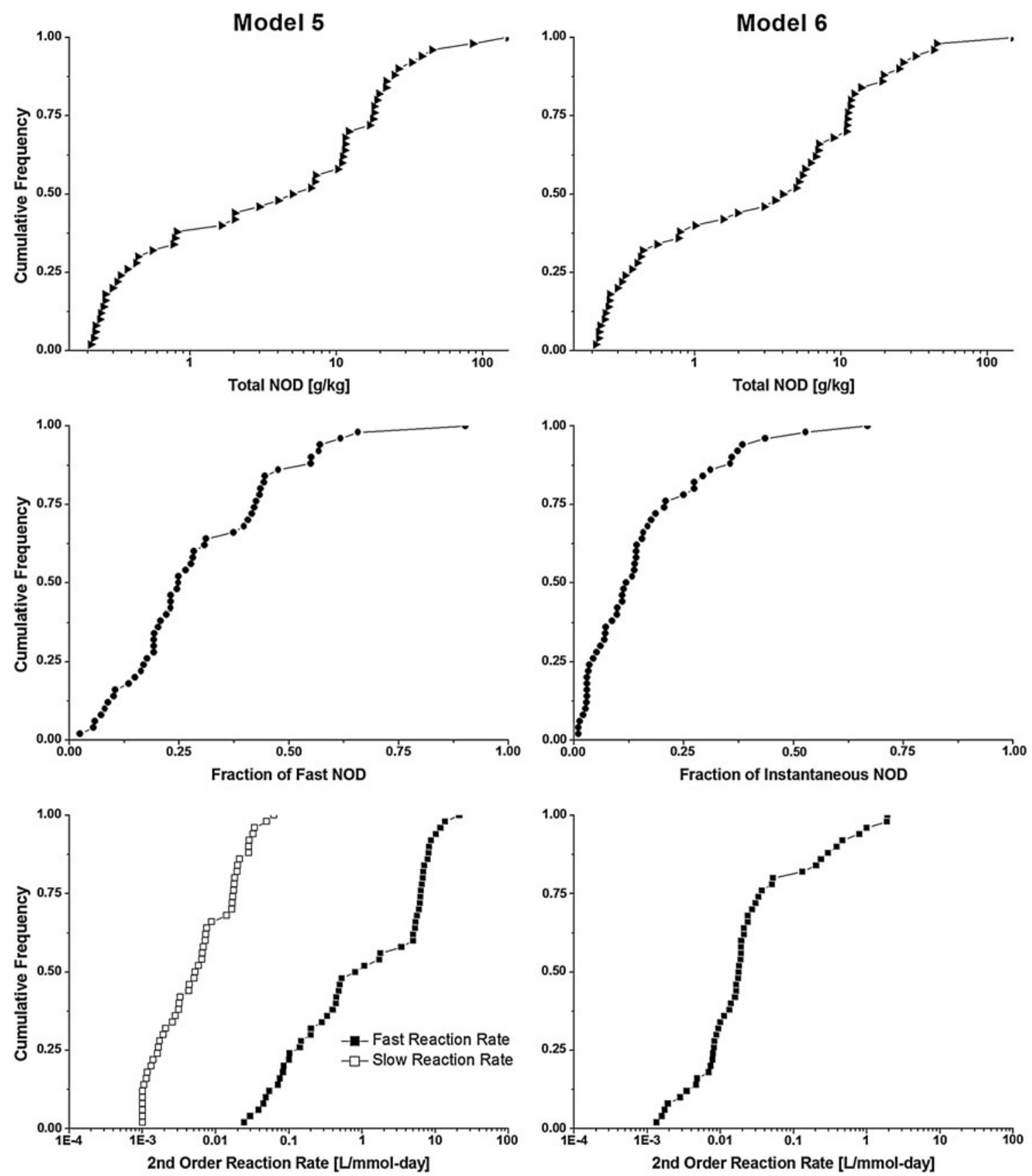

FIG. 4. Cumulative frequency distributions for Models 5 and 6: kinetic parameters generated using NOD data from 50 aquifer solids.

MAE and RMSE (Table 2). Consistent with the previous discussion, Model 5 provided the best fit to the data (lowest MAE and RMSE), followed by Model 6, then Model 4, then Model 3. Models 1 and 2 provided a poor fit to the experimental results. A Kruskal-Wallis nonparametric test was conducted to evaluate whether the performance of Model 6 was significantly different from that of Model 5 based on the distribution of absolute error (Ott and Longnecker, 2001). Using the pooled data from all 50 samples, the difference in the performance of Model 5 and 6 was significant at the 0.001 level. However, when applied to individual aquifer solids, there was no significant difference between Models 5 and 6 for 39 of the 50 samples $(78 \%)$. This indicates that for the total data set from the 50 aquifer solids, Model 5 is superior to Model 6 . However for many individual aquifer solid samples, the difference is not significant.

\section{NOD parameter estimates}

Parameter estimates and error statistics for Models 1 to 6 for the 50 aquifer solids are provided in Supplementary Tables S3 and S4. For Models 5 and 6, we report total NOD $\left(\mathrm{NOD}_{\mathrm{T}}\right)$ and the fraction fast or instantaneous (f) to simplify comparison between the different models and to be consistent with previous studies. $\mathrm{NOD}_{\mathrm{S}}=\mathrm{NOD}_{\mathrm{T}}(1-\mathrm{f})$ and $\mathrm{NOD}_{\mathrm{F}}$ and $\mathrm{NOD}_{\mathrm{I}}=\mathrm{NOD}_{\mathrm{T}} \times \mathrm{f}$. In most cases, parameter values were 
Table 3. Statistical Characteristics of Kinetic Parameter Distributions for Models 1-6 Generated Using Natural Oxidant Demand Data from 50 Aquifer Solids

\begin{tabular}{|c|c|c|c|c|c|c|c|}
\hline \multirow[b]{2}{*}{ Model } & \multirow[b]{2}{*}{ Parameter } & \multirow[b]{2}{*}{ Unit } & \multicolumn{5}{|c|}{ Percentile } \\
\hline & & & $10 \%$ & $25 \%$ & $50 \%$ & $75 \%$ & $90 \%$ \\
\hline 1 & $\mathrm{k}_{0}$ & mmol/L-day & 0.055 & 0.074 & 0.521 & 1.170 & 2.746 \\
\hline 2 & $\mathrm{k}_{1 \mathrm{M}}$ & 1/day & 0.010 & 0.015 & 0.035 & 0.077 & 0.290 \\
\hline 3 & $\begin{array}{l}\mathrm{NOD}_{\mathrm{T}} \\
\mathrm{k}_{1 \mathrm{~N}}\end{array}$ & $\begin{array}{l}\mathrm{mmol} / \mathrm{g} \\
1 / \text { day }\end{array}$ & $\begin{array}{l}0.001 \\
0.083\end{array}$ & $\begin{array}{l}0.002 \\
0.131\end{array}$ & $\begin{array}{l}0.027 \\
0.275\end{array}$ & $\begin{array}{l}0.069 \\
0.592\end{array}$ & $\begin{array}{l}0.158 \\
2.306\end{array}$ \\
\hline 4 & $\begin{array}{l}\mathrm{NOD}_{\mathrm{T}} \\
\mathrm{k}_{2}\end{array}$ & $\begin{array}{l}\mathrm{mmol} / \mathrm{g} \\
\mathrm{L} / \mathrm{mmol} \text {-day }\end{array}$ & $\begin{array}{l}0.001 \\
0.009\end{array}$ & $\begin{array}{l}0.002 \\
0.014\end{array}$ & $\begin{array}{l}0.027 \\
0.030\end{array}$ & $\begin{array}{l}0.069 \\
0.062\end{array}$ & $\begin{array}{l}0.158 \\
0.202\end{array}$ \\
\hline 5 & $\begin{array}{l}\mathrm{NOD}_{\mathrm{T}} \\
\text { Fraction instantaneous } \\
\mathrm{k}_{2 \mathrm{~F}} \\
\mathrm{~K}_{2 \mathrm{~S}}\end{array}$ & $\begin{array}{l}\mathrm{mmol} / \mathrm{g} \\
- \\
\mathrm{L} / \mathrm{mmol}-\text { day } \\
\mathrm{L} / \mathrm{mmol} \text {-day }\end{array}$ & $\begin{array}{l}0.002 \\
0.087 \\
0.053 \\
0.001\end{array}$ & $\begin{array}{l}0.002 \\
0.181 \\
0.143 \\
0.002\end{array}$ & $\begin{array}{l}0.037 \\
0.248 \\
0.944 \\
0.006\end{array}$ & $\begin{array}{l}0.114 \\
0.424 \\
6.329 \\
0.017\end{array}$ & $\begin{array}{l}0.172 \\
0.553 \\
8.245 \\
0.028\end{array}$ \\
\hline 6 & $\begin{array}{l}\mathrm{NOD}_{\mathrm{T}} \\
\text { Fraction instantaneous } \\
\mathrm{k}_{2 \mathrm{~S}}\end{array}$ & $\begin{array}{l}\mathrm{mmol} / \mathrm{g} \\
- \\
\mathrm{L} / \mathrm{mmol}-\text { day }\end{array}$ & $\begin{array}{l}0.002 \\
0.028 \\
0.003\end{array}$ & $\begin{array}{l}0.002 \\
0.046 \\
0.008\end{array}$ & $\begin{array}{l}0.028 \\
0.126 \\
0.018\end{array}$ & $\begin{array}{l}0.070 \\
0.208 \\
0.036\end{array}$ & $\begin{array}{l}0.158 \\
0.361 \\
0.395\end{array}$ \\
\hline
\end{tabular}

not normally or log normally distributed at the 0.05 level based on the Shapiro-Wilk test (Shapiro and Wilk, 1965). To provide a better representation of the parameter distributions, cumulative frequency plots for each of the Model 5 and 6 parameters are shown in Fig. 4 . The 10, 25, 50, 75, and 90 percentile values for every model parameter are summarized in Table 3.

Previous studies have reported large variations in the total amount of NOD. However, there is much less information on the fraction of fast/instantaneous NOD and reaction rate coefficients. In the 50 samples examined in this study, large variations in each of the parameters were observed, thus reflecting the wide variations in both the amount and reactivity of NOD in natural aquifer solids. Total NOD varied from 0.0013 to $0.95 \mathrm{mmol} / \mathrm{g}$ (equivalent to 0.2 to $150 \mathrm{~g} \mathrm{KMnO}_{4} / \mathrm{kg}$ ), similar to previously reported ranges (Siegrist et al., 2001; Mumford et al., 2005; Hønning et al., 2007; Urynowicz, 2008; $\mathrm{Xu}$ and Thomson, 2009). The fraction fast/instantaneous varied from $1 \%$ to $67 \%$ with a median of $13 \%$. The search procedure had a constraint that fraction fast/instantaneous $\geq 1 \%$. However, this constraint only influenced one out of the 50 samples. For Model 5, fast reaction rates varied from 0.02 to over $10 \mathrm{~L} / \mathrm{mmol}$-day, whereas the slow reaction rates were typically 1 to 2 orders of magnitude lower. Model 6 reaction rates were typically intermediate between the Model 5 fast and slow rates.

Some practitioners estimate the aquifer NOD based on the amount of $\mathrm{MnO}_{4}^{-}$consumed over $48 \mathrm{~h}$ as a screening test for potential ISCO sites (ASTM D 7262-07). Figure 5 shows the ratio of the best fit value of total NOD for Models 5 and 6 to the $48-\mathrm{h}$ value. This ratio varied widely, thus indicating that there is a very poor correlation between the best fit values of Total NOD to the 48 -h NOD. This indicates that 48 -h test results should not be used to estimate the amount of $\mathrm{MnO}_{4}^{-}$that may be consumed during extended incubation periods and should not be used to simulate $\mathrm{MnO}_{4}^{-}$consumption in transport models.

\section{Discussion}

Some remediation practitioners estimate the amount of $\mathrm{MnO}_{4}^{-}$required for ISCO based on a few short-term NOD measurements. Once injected, the $\mathrm{MnO}_{4}^{-}$concentration will vary in time and space due to advection, dispersion, and consumption by the contaminant and NOD. Previous studies have shown that $\mathrm{MnO}_{4}^{-}$consumption varies with time, that higher $\mathrm{MnO}_{4}^{-}$concentrations often result in greater demand, and that NOD may be composed of several components or fractions with varying reactivity (Siegrist, 2001; Mumford et al., 2005; Hønning et al., 2007; Urynowicz et al., 2008; Xu and Thomson, 2009). Given this previous work, there is no simple way to estimate the required injection concentration and volume from a few simple measurements. To reduce remediation system costs and improve performance, a simple, easy-to-implement approach is needed for estimating $\mathrm{MnO}_{4}^{-}$ distribution and longevity.

In this work, a simple procedure was developed and applied to estimate NOD kinetic parameters for six different models for 50 different samples of aquifer material. Consistent with previous work (Urynowicz, 2008; Xu and

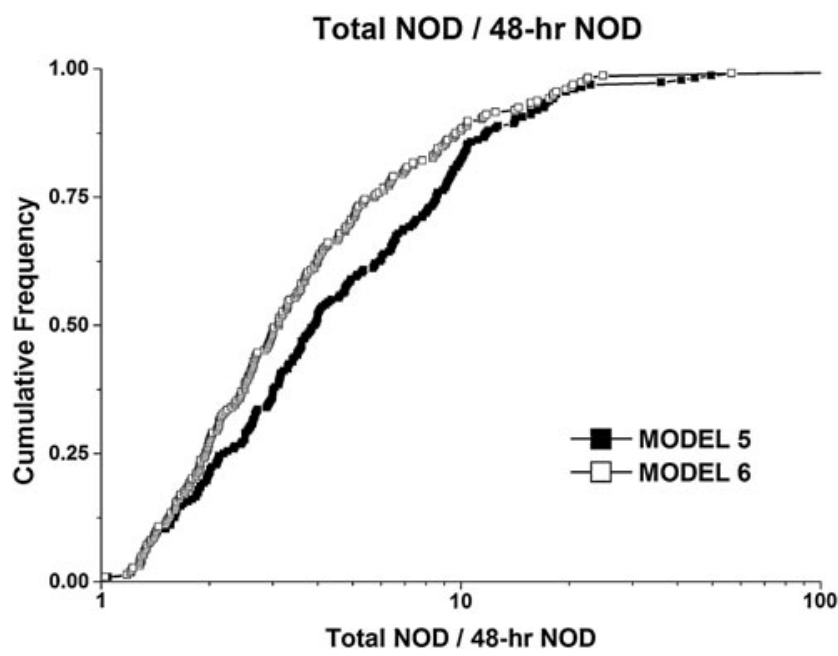

FIG. 5. Cumulative frequency distributions showing ratio of best fit total NOD to 48-h NOD for Models 5 and 6 using NOD data from 50 aquifer solids. 
Thomson, 2009), simulation of $\mathrm{MnO}_{4}^{-}$consumption as a second-order reaction with separate fast and slow NOD fractions provided the best fit to the experimental data. For the 50 samples examined in this study, the median half life $\left(\mathrm{T}_{1 / 2}\right)$ for $\mathrm{NOD}_{\mathrm{F}}$ was 0.02 days (range $=10^{-4}$ to 2 days), and median $\mathrm{T}_{1 / 2}$ for $\mathrm{NOD}_{\mathrm{S}}$ was 9.4 days (range $=10^{-2}$ to 84 days). These results indicate that (a) the fast NOD fraction will be rapidly consumed; and (b) once the fast fraction is depleted, remaining $\mathrm{MnO}_{4}^{-}$may persist for weeks to months, diffusing into lower permeability zones where contaminants may reside. However, accurate simulation of $\mathrm{MnO}_{4}^{-}$consumption by the fast fraction (Model 5) will require very short time steps with a proportionate increase in computer run times. In contrast, if the fast fraction is assumed to react instantaneously (Model 6), then the computational time step will be controlled by $\mathrm{NOD}_{\mathrm{S}}$ (median $T_{1 / 2}$ for $\mathrm{NOD}_{\mathrm{S}}=0.3$ day, range 0.01 to 64 days), resulting in an order of magnitude reduction in run times. Given the good performance of Model 6 in representing NOD kinetics in batch studies and the long residence time of $\mathrm{MnO}_{4}^{-}$in aquifers, use of Model 6 should allow accurate simulation of ISCO without imposing an unnecessary computational burden.

Wide variations in NOD parameters were observed including total NOD, fraction fast/instantaneous, and secondorder rate coefficients. In about one third of 50 samples, total $\mathrm{NOD}$ was greater than $0.06 \mathrm{mmol} / \mathrm{g}(10 \mathrm{~g} \mathrm{KMnO} 4 / \mathrm{kg}$ soil $)$ and, therefore, ISCO with $\mathrm{MnO}_{4}^{-}$may not be practical due to the large amounts of oxidant required. The fraction fast/instantaneous (f) typically varied between 0.05 and 0.2 , thus indicating most of the NOD exhibited behavior characteristic of the slow fraction. In general, these parameters were not normally or log normally distributed. Total NOD was not correlated $\left(r^{2}<0.2\right)$ with the fraction of fast/instantaneous NOD or the reaction rate coefficients for both Models 5 and 6, thus indicating that the total amount of NOD is not a good predictor of reactivity.

Given the large variations observed and poor correlation between these parameters, the kinetic model parameters should be measured for each site and/or aquifer material to be treated with $\mathrm{MnO}_{4}^{-}$. The batch NOD tests should be run for the range of $\mathrm{MnO}_{4}^{-}$concentrations and durations expected to occur in the field. NOD kinetic parameters can be estimated by following the procedures just described using the CDISCO (Conceptual Design of ISCO) tool (Borden et al., 2010; download at http://serdp-estcp.org) and then used to design ISCO systems using $\mathrm{MnO}_{4}^{-}$.

\section{Acknowledgment}

Financial support for K.Y. Cha was provided by the Environmental Security Technology Certification Program (ESTCP) under project ER-0625.

\section{Author Disclosure Statement}

No competing financial interests exist.

\section{References}

ASTM D 7262-07. (2007). Standard Test Method for Estimating the Permanganate Natural Oxidant Demand of Soil and Aquifer Solids. West Conshohocken, PA: ASTM International, 04.09.

Borden, R.C., Cha, K.Y., Simpkin, T., and Lieberman, M.T. (2010). Technical Report-Design Tool for Planning Permanganate Injection Systems. Environmental Science and Technology Certification Program, Washington, DC.

Crimi, M.L., and Siegrist, R.L. (2005). Factors affecting effectiveness and efficiency of DNAPL destruction using potassium permanganate and catalyzed hydrogen peroxide. J. Environ. Eng. ASCE. 131, 1724.

Hønning, J., Broholm, M.M., and Bjerg, P.L. (2007). Quantification of potassium permanganate consumption and PCE oxidation in subsurface materials. J. Contam. Hydrol. 90, 221.

Mumford, K.G., Thomson, N.R., and Allen-King, R.M. (2005). Bench-scale investigation of permanganate natural oxidant demand kinetics. Environ. Sci. Technol. 39, 2835.

Ott, R.L., and Longnecker, M. (2001). Introduction to Statistical Methods and Data Analysis, 5th edition. Belmont, CA: Duxbury Press.

Shapiro, S.S., and Wilk, M.B. (1965). An analysis of variance test for normality (Complete Samples). Biometrika 52, 591.

Siegrist, R.L., Urynowicz, M.A., West, O.R., Crimi, M., and Lowe, K.S. (2001). Principles and Practices of In Situ Chemical Oxidation Using Permanganate. Columbus, OH: Battelle Press.

Urynowicz, M.A. (2008). In situ chemical oxidation with permanganate: assessing the competitive interactions between target and nontarget compounds. Soil Sediment Contam. 17, 53.

Urynowicz, M.A., Balu, B., and Udayasankar, U. (2008). Kinetics of natural oxidant demand by permanganate in aquifer solids. J. Contam. Hydrol. 96, 187.

Xu, X., and Thomson, N.R. (2009). A long-term bench-scale investigation of permanganate consumption by aquifer materials. J. Contam. Hydrol. 110, 73.

Yan, Y.E., and Schwartz, F.W. (1999). Oxidative degradation and kinetics of chlorinated ethylenes by potassium permanganate. J. Contam. Hydrol. 37, 343.

Zhang, H., and Schwartz, F.W. (2000). Simulating the in situ oxidative treatment of chlorinated ethylenes by potassium permanganate. Water Resour. Res. 36, 3031. 